\title{
Environment-driven changes in terrestrial habitat use and distribution of the Galapagos sea lion
}

\author{
Ignasi Montero-Serra' ${ }^{1,2,3, *}$, Diego Páez-Rosas ${ }^{2,3,4}$, Juan C. Murillo ${ }^{2,5}$, \\ Teresa Vegas-Vilarrúbia ${ }^{1}$, Katharina Fietz ${ }^{3}$, Judith Denkinger ${ }^{3}$ \\ ${ }^{1}$ Departament d'Ecologia, Facultat de Biologia, Universitat de Barcelona, 08028 Barcelona, Spain \\ ${ }^{2}$ Dirección Parque Nacional Galápagos, Oficina Técnica San Cristóbal, 200150 Galápagos, Ecuador \\ ${ }^{3}$ Universidad San Francisco de Quito, Galápagos Science Center, San Cristóbal, 200150 Galápagos, Ecuador \\ ${ }^{4}$ Programa PROMETEO-SENESCYT, Secretaria Nacional de Educación Superior, Ciencia, \\ Tecnología e Innovación del Ecuador, 170135 Quito, Ecuador \\ ${ }^{5}$ Universidad Estatal Península de Santa Elena, Centro de Investigaciones Marinas, 240350 Santa Elena, Ecuador
}

\begin{abstract}
Understanding habitat use patterns of marine apex predators is of paramount importance for the effective design of conservation plans. Due to their amphibious life cycle, pinnipeds are one of the most vulnerable groups to habitat loss and degradation. Reducing knowledge gaps that still exist regarding temporal changes in tropical pinniped habitat use is therefore of particular importance for conservation efforts. We analyzed terrestrial habitat use phenology of a tropical otariid, the Galapagos sea lion Zalophus wollebaeki. Regular land-based censuses were carried out in Wreck Bay of San Cristóbal Island, Galapagos, between 2008 and 2012 to explore seasonal changes in sea lion abundance, distribution, and preferences among different habitat types. A daily cycle of haul-out patterns was observed. Animals aggregated on sandy beaches during the coldest periods of the day and were more abundant on rocky and artificial structures when air temperature was warmer. The use of artificial floating platforms as resting places by $Z$. wollebaeki was described for the first time and linked to environmental variability, suggesting that this may be a successful management tool for pinnipeds inhabiting low latitudes. Further, this species demonstrated seasonal distribution changes, aggregating in high densities during warm seasons and maintaining more even distributions during cold seasons. Sea surface temperature, air temperature, and the onset of the breeding season were the variables that most significantly influenced haul-out patterns of $Z$. wollebaeki, indicating that this species can adapt to changing environmental conditions by displaying a high degree of plasticity regarding its distribution and terrestrial microhabitat preferences.
\end{abstract}

KEY WORDS: Zalophus wollebaeki - Sea lion · Pinnipeds - Haul-out patterns · Galapagos · Habitat use $\cdot$ Environmental variability

\section{INTRODUCTION}

Marine ecosystems today are threatened by an increasing array of anthropogenic impacts that lead to multiple perturbations. Habitat destruction and degradation are among the most serious threats impacting coastal systems (Kappel 2005). Marine apex predators play an important role in these ecosystems. As top-down regulators of the food web, they have a key ecological function, the loss of which can result in cascading effects throughout ecosystems and on a global scale (Myers et al. 2007). The conservation of these species is therefore of paramount importance to preserve the integrity of marine 
ecosystems (Yodzis 2001, Baum \& Worm 2009). In recent decades, many studies have focused on understanding how apex predators respond to natural and anthropogenic perturbations (e.g. Hindell et al. 2003, Rosa \& Seibel 2008).

Pinnipeds are top predators in coastal areas and depend on terrestrial habitats or ice for breeding, molting, and raising their young (Bartholomew 1970, Riedman 1989). Due to their amphibious life-cycle, pinnipeds are particularly vulnerable to terrestrial habitat loss and degradation. Numerous pinniped populations have declined over the last century, and some species have become Extinct (Zalophus japonicus, Monachus tropicalis) or Critically Endangered (e.g. M. monachus, M. schauinslandi). As a result, awareness and concern regarding the status and conservation of seals and sea lions throughout the world has grown steadily in recent years (Costa et al. 2006).

Habitat selection is a hierarchical process composed of several innate and learned behavioral decisions made by individuals regarding their habitat preferences at different environmental scales (Hutto 1985). Potential drivers for terrestrial habitat selection in pinnipeds generally include predation risk and availability of shelter zones, proximity to feeding grounds, and the presence of suitable breeding and resting sites (Sigler et al. 2004, González-Suárez \& Gerber 2008, Womble et al. 2009). Nonetheless, various studies on temperate species have revealed that terrestrial habitat use patterns can vary depending on changing environmental parameters (Pauli \& Terhume 1987, Jemison et al. 2001).

As endotherms, pinnipeds experience thermal stress if temperatures rise above certain critical limits and they must therefore maintain a constant internal temperature in both aquatic and terrestrial environments. Pinnipeds are adapted to the aquatic environment, having developed several morphological features to reduce heat loss when foraging in cold waters. Conversely, they are exposed to solar radiation and absorb heat directly through their skin when resting on land. The warming of the surrounding substrates reduces the heat gradient and minimizes heat loss, even adding heat gain through conduction (Campagna \& Le Boeuf 1988, Norris et al. 2010). Thus, the thermoregulation response is especially challenging for pinnipeds due to the differences in thermal fluxes in both environments and also because their large body size limits the effectiveness of surface heat loss (Norris et al. 2010). Behavioral responses such as the thermoregulation mechanism are known to be important drivers of haul-out pat- terns in many temperate pinniped species (White \& Odell 1971, Witthow et al. 1971, Odell 1974, Campagna \& Le Boeuf 1988, Francis \& Boness 1991, Twiss et al. 2002). However, little is known about temporal variations in haul-out behavior and thermoregulation of pinnipeds inhabiting low latitudes.

Among pinnipeds, tropical otariids are particularly dependent on terrestrial habitat, as they have extended lactation periods of up to $3 \mathrm{yr}$ due to food scarcity (Elorriaga-Verplancken 2009, VillegasAmtmann et al. 2009). Two endemic species of otariids, the Galapagos sea lion (GSL) Zalophus wollebaeki and the Galapagos fur seal Arctocephalus galapagoensis, live under such conditions in the Galapagos Archipelago. Morphological, physiological, and behavioral adaptations have allowed them to survive in this environment, where they face a periodic lack of feeding resources (Villegas-Amtmann et al. 2009, Jeglinski et al. 2012, Páez-Rosas et al. 2012).

The GSL is found around all major islands of the Galapagos, with the larger colonies located in the South and East of the archipelago. The species was listed as Endangered in the Red List of Threatened Species by the International Union for Conservation of Nature (IUCN) due to a large population reduction of approximately $50 \%$ over the past 30 yr (Aurioles \& Trillmich 2008). Among the major threats are introduction of new diseases through human and animal contact (i.e. cats, dogs, rats), bycatch and entanglement, marine pollution, and habitat loss and degradation. The negative consequences of anthropogenic disturbances may be amplified by acting synergistically with El Niño-Southern Oscillation (ENSO) events that occur periodically in the Galapagos, leading to a lack of feeding resources in the marine environment (Trillmich \& Limberger 1985, Salazar 2003, Palacios 2004, Alava \& Salazar 2006, Alava et al. 2011, Brock et al. 2013, Hanna \& Cardillo 2013).

Today, the GSL is protected within the Galapagos Marine Reserve and is the focus of conservation efforts of many local and international organizations. One of these projects aimed to provide undisturbed resting sites and to reduce anthropogenic disturbances by installating 3 floating platforms in Wreck Bay (WB) on San Cristóbal Island, where the presence of invasive species and the recent habitat degradation represent major threats to the sea lion population. This is an innovative wildlife management tool that could bring potential benefits for the conservation of this Endangered species. However, knowledge is still lacking about the temporal dynamics of habitat use patterns in tropical pinnipeds, which makes it difficult to evaluate and 
improve these kinds of management and conservation actions.

In the present study, we aim to reduce existing knowledge gaps by investigating the patterns and phenology of terrestrial habitat use and movements of GSL in WB at different temporal scales. Specifically, we aim to explore changes in abundance, distribution, and terrestrial microhabitat preferences at a seasonal and daily scale and test whether the observed changes are driven by the high environmental variability of the Galapagos Islands.

\section{MATERIALS AND METHODS}

\section{Study area}

The study was conducted in WB on San Cristóbal Island $\left(0^{\circ} 54^{\prime} 8.1^{\prime \prime} \mathrm{S}, \quad 89^{\circ} 36^{\prime} 44.1^{\prime \prime} \mathrm{W}\right)$, a long-established breeding and resting site for GSL. Five beaches are found in WB: Zona Naval (ZN), Los Marinos (LM), Playa de Oro (PO), Playa Mann (PM), and Carola (CA) (Fig. 1). The main beaches are separated by rocky areas. Two artificial wooden floating platforms $\left(25 \mathrm{~m}^{2}\right)$ and numerous small boats in WB serve as resting places for the sea lions (boats and platforms are henceforth referred to as 'artificial structures').

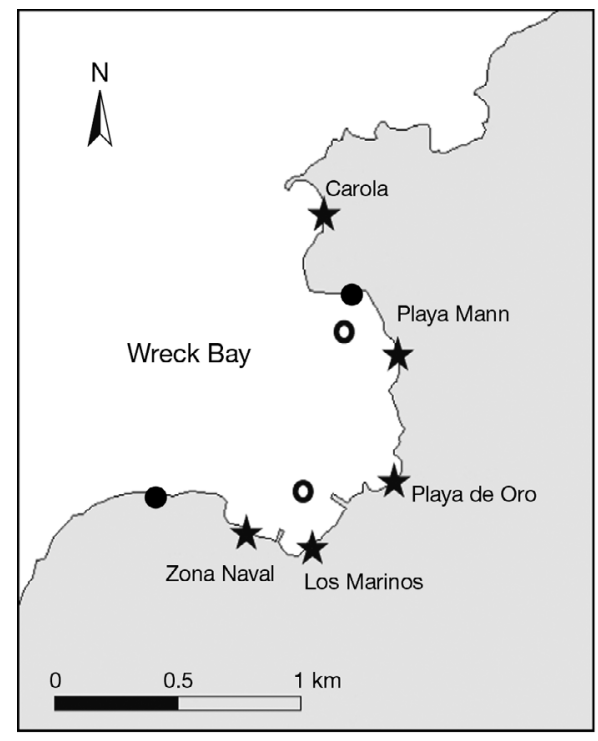

Fig. 1. Study area: Wreck Bay of San Cristóbal Island $\left(0^{\circ} 54^{\prime}\right.$ 8.1" S, 89³6'44.1" W), Galapagos. Left: main beaches ( $\star$ ), rocky areas ( ), and floating platforms (O) are identified. Between 60 and 80 boats were anchored in Wreck Bay during the study period but their exact position was not recorded for this study. Upper right: Galapagos Islands to the west of South America; lower right: San Cristóbal Island in the Galapagos Islands

\section{Data collection}

From 2008 to 2012, a total of 455 land-based surveys were conducted, in which the total number of animals, age class, and sex were recorded according to the classification by Wolf et al. (2005). Between May and August 2011, we complemented these data with a total of 486 regular censuses $(n=54)$ in each of the 9 study sites (5 sandy beaches, 3 rocky areas, and artificial structures) twice per day to account for daily variation: at sunrise (06:00 h) to observe the nocturnal behavior of the species with a minimum degree of disturbance, and $1 \mathrm{~h}$ after midday (13:00 h) to observe behavior during periods of maximum air temperature. In total, 941 censuses were included in the analysis. For each survey, we recorded air temperature, tide level, and weather conditions. Weather conditions were defined using a 3-level scale (1 = sunny with no clouds; 2 = sky partially covered; $3=$ sky completely covered). Sea surface temperature (SST) was obtained from the National Oceanic and Atmospheric Administration website (www.noaa.gov).

\section{Data analysis}

To determine the factors that influence changes in sea lion distribution and habitat preferences, we ap-

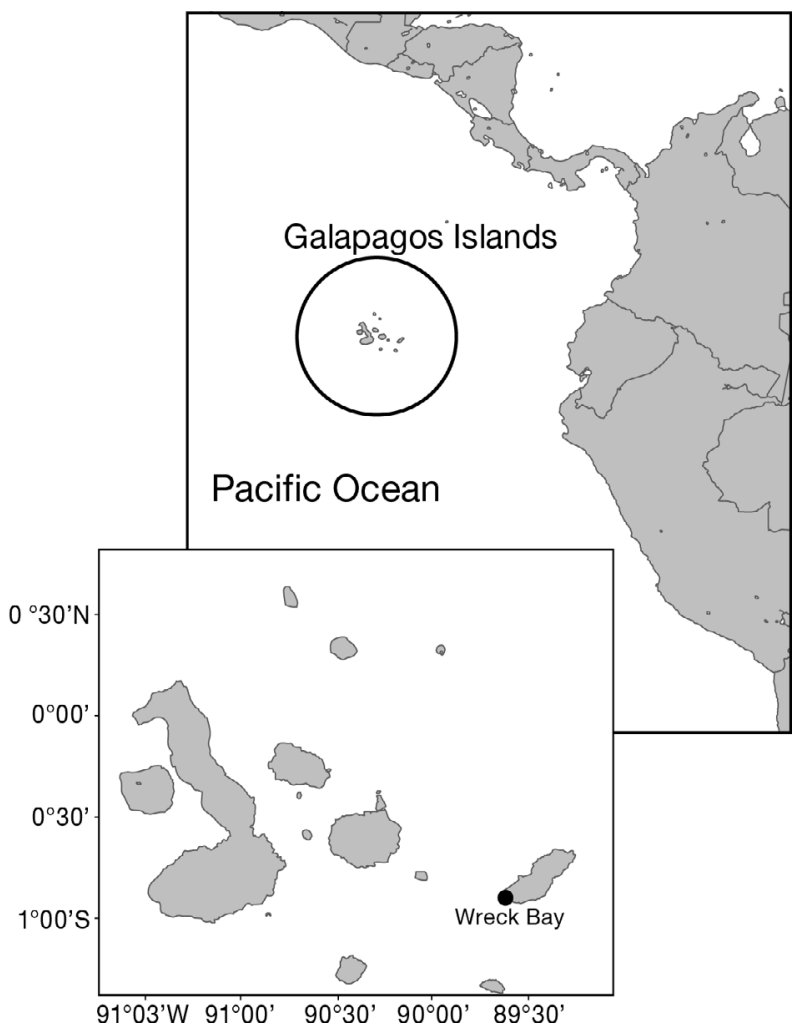


plied generalized linear models (GLMs) at 2 different temporal scales: seasonal and diurnal. GLMs allow for a wide range of non-normal error distributions, and have the ability to work with some nonlinear functions (McCullagh \& Nelder 1989). They were therefore the most appropriate for use in the present study. Due to an over-dispersion of the data (deviance/df $>2$ ), the models were adjusted with a negative binomial distribution, which included an extra parameter describing dispersion. As this parameter approaches 0, over-dispersion decreases and the negative binomial distribution approaches a Poisson distribution.

The most suitable model was selected using an information-theoretic approach (Burnham \& Anderson 2002). This approach requires the development of a set of plausible candidate models based on a priori predictions. In the present study, all recorded variables were hypothesized a priori to affect sea lion occupancy of a given site, and all potential models resulting from linear combinations of uncorrelated variables were considered. The limit for keeping a variable in the final model was set at $p<0.05$. To aid model selection, we used Akaike's information criterion corrected for small sample sizes $\left(\mathrm{AIC}_{\mathrm{c}}\right)$, the difference in $\mathrm{AIC}_{\mathrm{c}}$ between each model and the model with the lowest $\mathrm{AIC}_{\mathrm{c}}\left(\Delta \mathrm{AIC}_{\mathrm{c}}\right)$, and $\mathrm{AIC}_{\mathrm{c}}$ weight $\left(w_{i}\right)$. The model with the lowest $\mathrm{AIC}_{\mathrm{c}}$ and those with $\Delta \mathrm{AIC}_{\mathrm{C}} \leq 2$ were considered to be supported. $\mathrm{AIC}_{\mathrm{c}}$ was calculated using the following equations:

$$
\begin{gathered}
\mathrm{AIC}=-2 L+2 k \\
\mathrm{AIC}_{\mathrm{c}}=\mathrm{AIC}+2 k(k+1) /(n-k-1)
\end{gathered}
$$

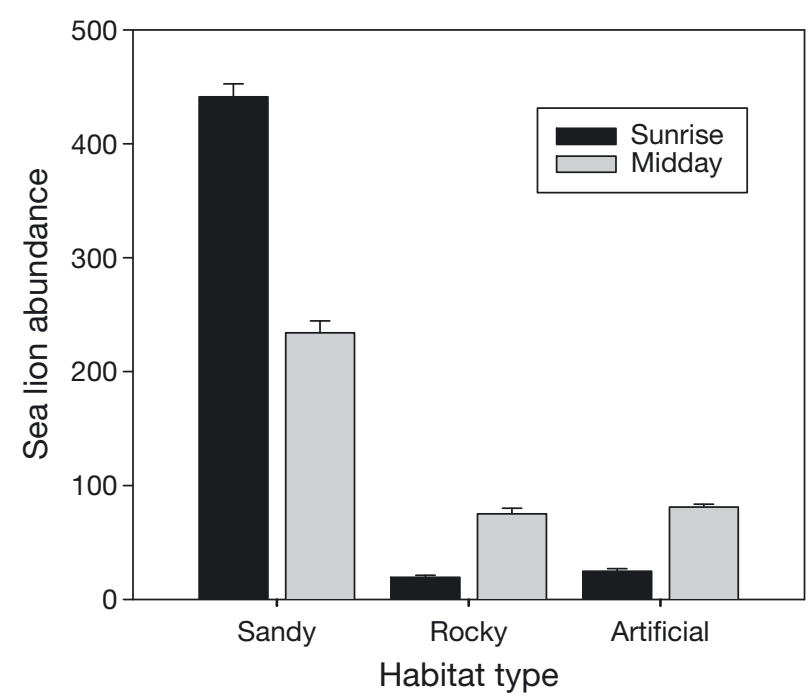

Fig. 2. Zalophus wollebaeki. Mean $\pm \mathrm{SE}$ of animals counted in the 3 habitat types in Wreck Bay, Galapagos: sandy beaches $(\mathrm{n}=54)$, rocky areas $(\mathrm{n}=54)$, and artificial structures $(\mathrm{n}=50)$. Censuses were conducted regularly at sunrise $(06: 00 \mathrm{~h})$ and $1 \mathrm{~h}$ after midday (13:00 h) from May to August 2011 where $L$ is the log-likelihood, $k$ is the number of parameters in the model, and $n$ is the number of observations. Furthermore, the amount of variance that the models explained $\left(\mathrm{D}^{2}\right)$ was calculated using the equation:

$$
\mathrm{D}^{2}=[(\mathrm{ND}-\mathrm{RD}) / \mathrm{ND}] \times 100
$$

where ND is the null deviance of the data and RD is the residual deviance.

To determine whether abundance changes resulted from internal movements between WB sites, Spearman correlations were conducted for observed abundances on the 5 main haul-out sites during the study period (2008 to 2012). All analyses were conducted using the software language R ( $\mathrm{R}$ Development Core Team 2008).

\section{RESULTS}

\section{Changes in terrestrial microhabitat preferences}

GSL terrestrial habitat preferences altered throughout the day. An average of $448 \pm 13$ (SE) animals were counted at sunrise $(06: 00 \mathrm{~h})$, with $91 \%$ observed on sandy beaches, $5 \%$ on artificial structures, and the remaining $4 \%$ in rocky areas. In contrast, we counted an average of $390 \pm 8$ (SE) animals $1 \mathrm{~h}$ after midday $(13: 00 \mathrm{~h})$, of which $60 \%$ were observed on sandy beaches, $21 \%$ on artificial structures, and $19 \%$ in rocky areas (Fig. 2).

To analyze the influence of environmental drivers of GSL habitat preferences, we applied a set of GLMs for 3 microhabitat types present in WB (sandy beaches, rocky areas, and artificial structures). Air temperature, time of day, weather conditions, and tide level demonstrated significant effects on the abundance of animals. As time of day and air temperature revealed high correlation (Kendall's tau $=0.7$; $\mathrm{p}<0.001$ ), we only included air temperature in the final models.

Air temperature was present in the best fitted models for the 3 analyzed habitat types (Table 1). On sandy beaches, abundance decreased with increases in air temperature, whereas on rocky areas and artificial structures, the observed pattern was the opposite, with abundance increasing along with air temperature (Fig. 3). Tide level indicated a significant but weaker effect on sea lion abundance on sandy beaches and rocky areas, with slight increases on sandy beaches and a simultaneous decrease on rocky areas at high tide. The use of artificial structures as resting habitat was also influenced by weather con- 
Table 1. Model selection and criteria utilized in the analysis of changes in habitat preferences and influencing factors in each habitat type. Supported models $\left(\Delta \mathrm{AIC}_{\mathrm{c}} \leq 2\right)$ are marked in bold. Temperature: air temperature; $k$ : number of parameters in the model $\%$ Var: \% variance explained by the model; $\mathrm{AIC}_{\mathrm{c}}$ : Akaike's information criterion corrected for small sample sizes; $\Delta \mathrm{AIC}_{\mathrm{c}}$ : difference in $\mathrm{AIC}_{\mathrm{c}}$ between each model and the model with the lowest $\mathrm{AIC}_{\mathrm{C}}$

\begin{tabular}{|c|c|c|c|c|c|}
\hline Site & Model & $k$ & $\%$ Var & $\mathrm{AIC}_{\mathrm{c}}$ & $\Delta \mathrm{AIC}_{\mathrm{C}}$ \\
\hline \multirow[t]{6}{*}{ Sandy areas $(\mathrm{n}=54)$} & Temperature & 2 & 69.27 & 610.1 & $\mathbf{0}$ \\
\hline & Temperature + Tide & 4 & 70.68 & 611.8 & 1.6 \\
\hline & Temperature + Weather & 4 & 70.33 & 612.4 & 2.3 \\
\hline & Temperature + Weather + Tide & 6 & 72.26 & 613.9 & 3.8 \\
\hline & Temperature + Weather + Tide + Date & 7 & 73.59 & 614 & 3.9 \\
\hline & Temperature $\times$ Weather & 6 & 71.09 & 616.2 & 6 \\
\hline \multirow[t]{6}{*}{ Rocky areas $(\mathrm{n}=54)$} & Temperature + Tide & 4 & 76.38 & 446.2 & $\mathbf{0}$ \\
\hline & Temperature $\times$ Tide & 6 & 77.49 & 448.8 & 2.7 \\
\hline & Temperature + Weather + Tide + Date & 7 & 77.62 & 451.2 & 5.1 \\
\hline & Temperature + Weather + Tide & 6 & 76.39 & 451.3 & 5.2 \\
\hline & Temperature & 2 & 71.26 & 451.8 & 5.6 \\
\hline & Temperature + Weather & 4 & 71.42 & 456.2 & 10.1 \\
\hline \multirow[t]{7}{*}{ Artificial structures $(n=50)$} & Temperature & 2 & 90.82 & 362.9 & 0 \\
\hline & Temperature + Weather & 4 & 91.42 & 364.5 & 1.6 \\
\hline & Temperature $\times$ Tide & 6 & 92.04 & 366 & 3.1 \\
\hline & Temperature + Tide & 4 & 90.88 & 367.3 & 4.4 \\
\hline & Temperature + Tide + Weather & 6 & 91.6 & 368.6 & 5.8 \\
\hline & Temperature $\times$ Weather & 6 & 91.56 & 369 & 6.1 \\
\hline & Temperature + Weather + Tide + Date & 7 & 91.78 & 370.4 & 7.1 \\
\hline
\end{tabular}

ditions, as more animals were observed on sunny days compared to cloudy days. The strong effect of air temperature on GSL habitat preferences was supported by a strong correlation between animal abundance and habitat type: negative on sandy beaches $\left(\mathrm{R}^{2}=0.71 ; \mathrm{p}<0.01\right)$, and positive on rocky areas $\left(\mathrm{R}^{2}=\right.$ $0.65 ; \mathrm{p}<0.01)$ and artificial structures $\left(\mathrm{R}^{2}=0.89 ; \mathrm{p}<\right.$ 0.01) (Fig. 3).

\section{Seasonal changes in distribution}

GSL revealed terrestrial distribution changes between seasons. While the total number of individuals in WB did not demonstrate significant seasonal differences, a high degree of seasonality in the number of animals per haul-out site within the bay occurred. During warm seasons, LM beach maintained a high abundance of animals, while at the remaining beaches, abundance was low; during cold seasons, animals distributed more evenly between haul-out sites (Figs. 4 \& 5). The seasonal reduction in sea lion numbers observed at LM was approximately $50 \%$, while numbers increased by $74 \%$ at PM, by $49 \%$ at CA, and by $37 \%$ in ZN (Fig. 5). No seasonal patterns were observed at $\mathrm{PO}$, the smallest haul-out site, where mainly adult males were found (Fig. A1 in the Appendix). The variables that best explained the observed fluctuations and distribution changes were: season, time of day, and year. Season had a significant influence and was present in the best fitted models for the 4 primary haul-out sites analyzed (CA, $\mathrm{PM}, \mathrm{ZN}$, and LM), confirming its influence on sea lion colony dynamics (Table 2). Further, in terms of temporal changes in abundance, the 4 main beaches (CA, PM, ZN, and LM) appeared to be highly correlated (Table 3).

\section{DISCUSSION}

We investigated temporal dynamics of terrestrial habitat use of GSL in WB of San Cristóbal Island and observed seasonal and daily changes in their haulout behavior and microhabitat preferences related to environmental variability.

\section{Changes in terrestrial microhabitat preferences}

GSL terrestrial microhabitat preferences change throughout the daily cycle and are linked to air temperature and weather conditions. A fine-scale temporal analysis revealed a clear daily pattern in their terrestrial haul-out behavior; most animals rest on sandy beaches at sunrise when air temperatures are low, and change to artificial structures and rocky areas at midday when temperatures are higher. 

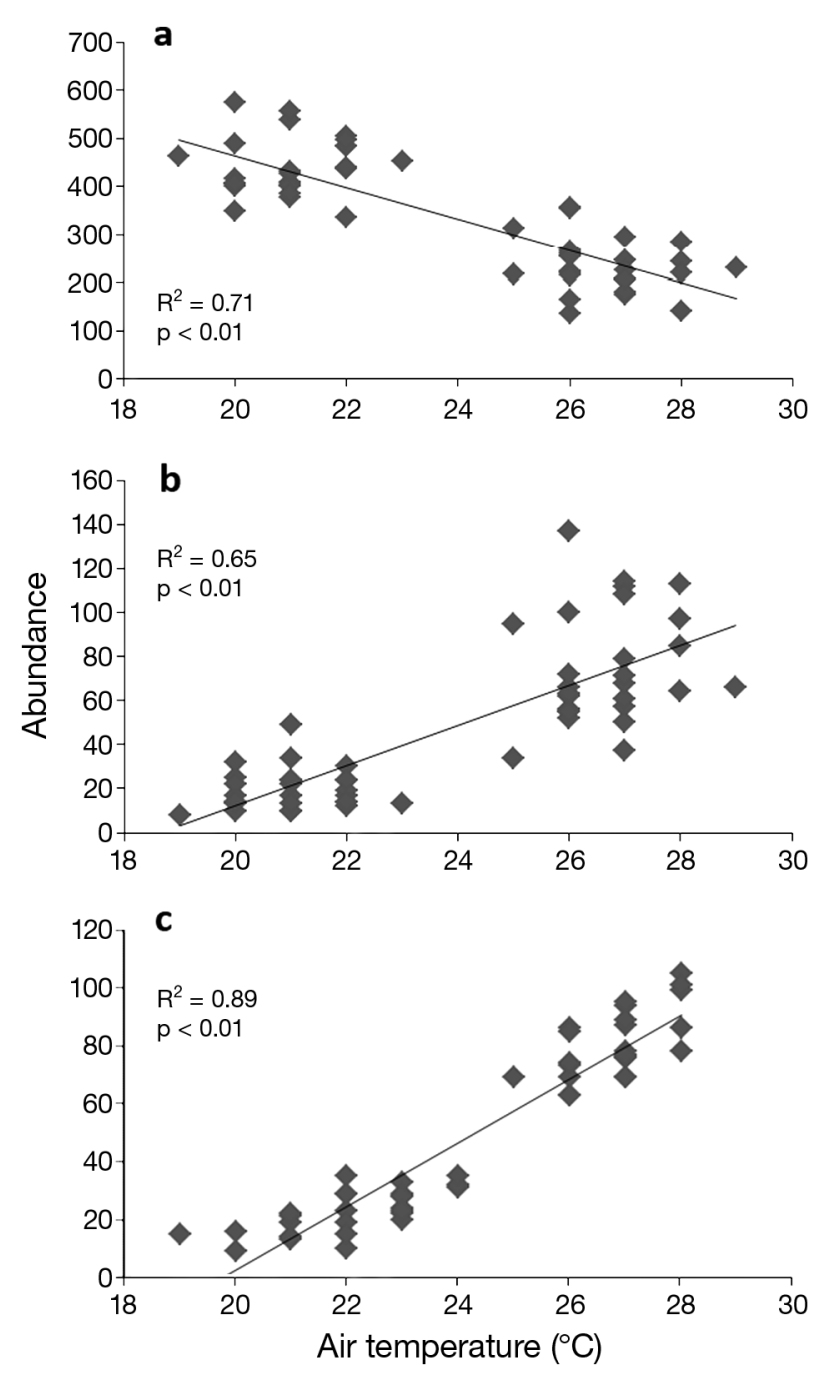

Fig. 3. Zalophus wollebaeki. Relationship between observed number of animals and air temperature in the 3 analyzed habitat types: (a) sandy areas $(\mathrm{n}=54)$, (b) rocky areas $(\mathrm{n}=54)$, and $(\mathrm{c})$ artificial structures $(\mathrm{n}=50)$

Among all analyzed environmental parameters, air temperature was the most influencing variable in all 3 habitat types. The high correlation between air temperature and observed abundances supports the hypothesis that climatic forces are an important driver of GSL haul-out preferences. Sandy beaches were more intensively used during the coolest periods, while rocky areas revealed higher abundances at warmer times of day (Fig. 2). Within WB, sandy beaches are generally protected from the cold winds, a feature that would provide a suitable resting place during the cooler times of day. The gregarious behavior of this species on flat substrates allows for increased direct contact between individuals, and it may help animals to reduce heat loss,

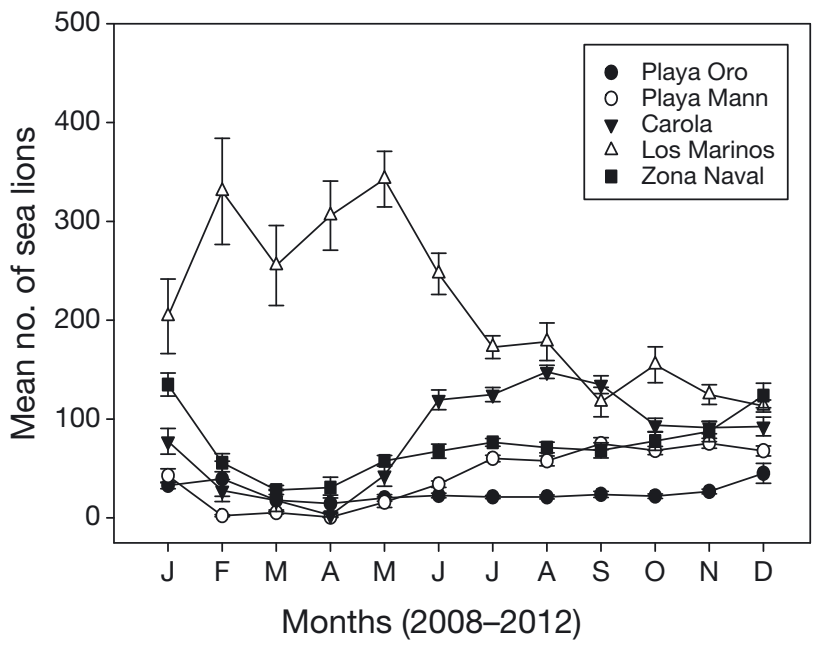

Fig. 4. Zalophus wollebaeki. Temporal changes in terrestrial distribution of Galapagos sea lions during the year. Monthly mean $\pm \mathrm{SE}$ of animals counted in 5 main haul-out sites in Wreck Bay, Galapagos, during the study period (2008 to 2012)

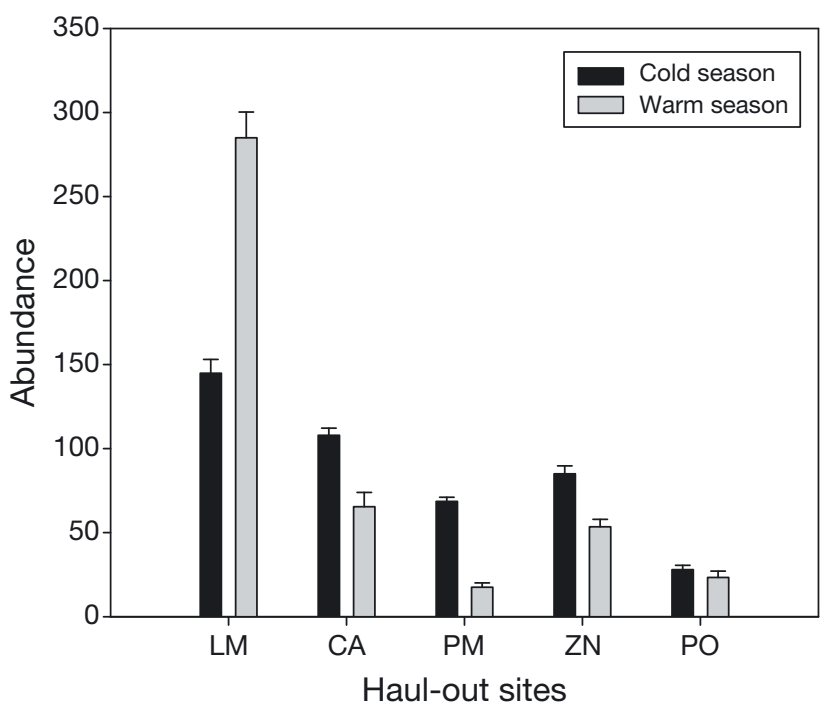

Fig. 5. Zalophus wollebaeki. Mean \pm SE of animals counted in 5 main haul-out sites in Wreck Bay, Galapagos, during the study period (2008 to 2012), in the cold season (July to November) and the warm season (January to May). See Table 2 for site abbreviations

as suggested for the New Zealand sea lion Phocarctos hookeri, which enacts behavioral changes during cooler times of day to avoid overcooling (Beentjes 2006). On the other hand, as observed for the GSL's congener, the California sea lion Zalophus californianus, rocky areas may play a key role in thermoregulation processes during periods of high temperatures, as they provide direct access to water and their complex structure increases shaded 
Table 2. Model selection and criteria utilized in the analysis of seasonal changes in abundance and distribution for each site studied. Supported models $\left(\Delta \mathrm{AIC}_{\mathrm{c}} \leq 2\right)$ are marked in bold. See Table 1 for abbreviations. CA: Carola; PM: Playa Mann; PO: Playa de Oro; LM: Los Marinos; ZN: Zona Naval

\begin{tabular}{|c|c|c|c|c|c|}
\hline Site & Model & $k$ & $\%$ Var & $\mathrm{AIC}_{\mathrm{C}}$ & $\Delta \mathrm{AIC}_{\mathrm{C}}$ \\
\hline LM (n = 216) & $\begin{array}{l}\text { Year }+ \text { Season }+ \text { Time } \\
\text { Year } \times \text { Season }+ \text { Time } \\
\text { Season } \times \text { Time } \\
\text { Year }+ \text { Season } \times \text { Time } \\
\text { Season }+ \text { Time }\end{array}$ & $\begin{array}{c}7 \\
\mathbf{9} \\
12 \\
13 \\
6\end{array}$ & $\begin{array}{c}\mathbf{5 7 . 7} \\
\mathbf{5 9 . 6} \\
60.7 \\
61 \\
57.8\end{array}$ & $\begin{array}{l}\mathbf{2 3 7 0 . 4} \\
\mathbf{2 3 7 4 . 1} \\
2375.2 \\
2375.8 \\
2377.5\end{array}$ & $\begin{array}{c}\mathbf{0} \\
\mathbf{3 . 6} \\
4.7 \\
5.4 \\
7.1\end{array}$ \\
\hline $\mathrm{CA}(\mathrm{n}=209)$ & $\begin{array}{l}\text { Season } \times \text { Time } \\
\text { Year }+ \text { Season } \times \text { Time } \\
\text { Year } \times \text { Season }+ \text { Time }\end{array}$ & $\begin{array}{l}12 \\
13 \\
15\end{array}$ & $\begin{array}{l}32.1 \\
32.5 \\
32.7\end{array}$ & $\begin{array}{l}2225.5 \\
2226.2 \\
2232.8\end{array}$ & $\begin{array}{l}\mathbf{0} \\
\mathbf{0 . 7} \\
7.2\end{array}$ \\
\hline $\mathrm{PM}(\mathrm{n}=203)$ & $\begin{array}{l}\text { Year + Season + Time } \\
\text { Year + Season + Time + Date }\end{array}$ & $\begin{array}{c}\mathbf{9} \\
12\end{array}$ & $\begin{array}{l}\mathbf{6 7 . 3} \\
58.9\end{array}$ & $\begin{array}{c}\mathbf{1 7 4 5 . 9} \\
1784\end{array}$ & $\begin{array}{c}\mathbf{0} \\
38.2\end{array}$ \\
\hline $\mathrm{ZN}(\mathrm{n}=141)$ & $\begin{array}{l}\text { Year + Season + Time } \\
\text { Season + Time } \\
\text { Year + Season + Time + Date }\end{array}$ & $\begin{array}{l}9 \\
6 \\
8\end{array}$ & $\begin{array}{l}32.7 \\
28.6 \\
29.5\end{array}$ & $\begin{array}{l}\mathbf{1 3 5 6 . 1} \\
1358.1 \\
1360.7\end{array}$ & $\begin{array}{c}\mathbf{0} \\
2.1 \\
4.6\end{array}$ \\
\hline $\mathrm{PO}(\mathrm{n}=177)$ & $\begin{array}{l}\text { Year } \times \text { Season }+ \text { Time } \\
\text { Year }+ \text { Month }+ \text { Date }+ \text { Tide }+ \text { Time } \\
\text { Year }+ \text { Season }+ \text { Date }+ \text { Tide }+ \text { Time }\end{array}$ & $\begin{array}{l}\mathbf{1 7} \\
11 \\
12\end{array}$ & $\begin{array}{l}36.9 \\
24.7 \\
22.6\end{array}$ & $\begin{array}{l}\mathbf{1 3 8 0 . 6} \\
1386.6 \\
1386.7\end{array}$ & $\begin{array}{c}\mathbf{0} \\
6 \\
6.1\end{array}$ \\
\hline
\end{tabular}

area availability, thereby reducing direct solar radiation (Thompson et al. 1987, González-Suárez \& Gerber 2008). This behavioral thermoregulatory mechanism, described for the first time in a tropical pinniped in the present paper, the GSL, is shared by other temperate pinnipeds. Southern sea lions Otaria flavescens, Juan Fernandez fur seals Arctocephalus philippii, and grey seals also use behavioral thermoregulatory mechanisms, demonstrating movements towards shorelines and into the ocean in summers, when temperatures are high (Campagna \& Le Boeuf 1988, Francis \& Boness 1991, Twiss et al. 2002). Our results are in agreement with Wolf et al. (2005), who suggested that GSL habitat preferences are linked to thermoregulatory requirements.

Table 3. Matrix of Spearman rank correlation coefficients among sea lion abundances at the various sites of Wreck Bay (WB), Galapagos, during the study period (2008 to 2012). Relationships with total abundance in WB and sea surface temperature (SST) were also included. See Table 2 for site abbreviations. *Significant relationships at $\mathrm{p}<0.05$

\begin{tabular}{|lcccccc|}
\hline & CA & PM & PO & LM & ZN Total WB \\
\hline CA & & & & & & \\
PM & $0.73^{*}$ & & & & & \\
PO & 0.09 & -0.02 & & & & \\
LM & $-0.51^{*}$ & $-0.74^{*}$ & 0.16 & & & \\
ZN & 0.36 & $0.52^{*}$ & 0.10 & $-0.52^{*}$ & & \\
Total WB & $0.42^{*}$ & $0.51^{*}$ & $0.48^{*}$ & $-0.53^{*}$ & 0.21 & \\
SST & $-0.46^{*}$ & $-0.67^{*}$ & $-0.07^{*}$ & $0.33^{*}$ & $-0.37^{*}$ & 0.21 \\
\hline
\end{tabular}

While pinnipeds using wooden floating platforms have been observed previously (e.g. the California sea lion Zalophus californianus in San Francisco Bay), the present study described and analyzed quantitatively this behavior for the first time. The high correlation with air temperature and weather suggests that those structures provide advantages to GSL for thermoregulation processes (Fig. 2). Artificial structures may represent a suitable resting place during periods of high temperature to optimize GSL's thermoregulatory requirements, as these provide rapid access to the water and shaded areas similar to the observed features of rocky areas. This behavioral adaptive capability would therefore indicate that GSL display a high degree of plasticity regarding habitat preferences, possibly allowing them to use new substrates as an extension of their own natural habitat. Given the observed capability of sea lions to use artificial structures as a resting place and the observed adaptations of this population in a human-modified environment, it is likely that similar patterns will occur in other pinniped populations after construction of marine structures (e.g. oil rigs). Thus, an assessment of pinnipeds' habitat preferences prior to any construction that could provide new substrates for these animals should be required in order to understand potential impacts on wild populations and to be able to minimize them.

The results presented here have important implications for the management of this species, as they highlight the importance of enforcing preservation of suitable habitat for thermoregulation requirements. Further, this study reveals that artificial 
floating structures can be a relatively simple and cheap management tool useful at the local scale for providing a suitable substrate for rest during warm and energetically costly moments. This finding might be of interest in light of current global warming. Climatic models predict an increase of temperature between 2 and $3^{\circ} \mathrm{C}$ by the year 2100 in the Galapagos Islands area (IPCC 2007), and this increment may enhance GSL thermal stress during the warmest periods of the year.

\section{Seasonal changes in distribution}

GSL demonstrated seasonal changes in distribution linked to environmental variables. During warm seasons, sea lions aggregated in high densities on one of the beaches, while very few individuals were observed on the other beaches in WB. In contrast, during cold seasons, sea lions changed their haul-out patterns, showing a more even distribution across all the main beaches of WB. The observed changes between haul-out sites were highly correlated, suggesting that fluctuations in abundances among sites were caused by movements within WB and were not due to migrations or movements between different colonies from outside of WB (Table 2).

While several authors have described seasonal changes in habitat use and distribution in pinnipeds inhabiting temperate areas (Krieber \& Barrette 1984, Montgomery et al. 2007), the present study represents the first time that a seasonal pattern of distribution change has been observed in a low-latitude pinniped. In higher latitudes, seasonal movements are often driven by proximity to feeding grounds (Jonker \& Bester 1998); this determinant is unlikely to explain our results, as the movements undertaken by GSL in WB are shorter than $1 \mathrm{~km}$, while this species moves average distances of $42 \mathrm{~km}$ for feeding (Villegas-Amtmann et al. 2009). Among other factors, molting periods and annual breeding cycles have been reported to influence seasonal changes in the distribution of pinnipeds (Rosas et al. 1994, Carlens et al. 2006, Leeney et al. 2010). GSL do not experience an annual molting period; however, the seasonal influence of the breeding cycle likely affects the species' habitat preferences, as the observed movements and distribution changes throughout the present study are in accordance with breeding activities. Although previous studies reported long-term site fidelity for this species (Wolf \& Trillmich 2007, Meise et al. 2013), we observed seasonal variations throughout the year that result in 2 distinct situations: (1) an aggregation period in 1 haul-out site during non-breeding seasons, aligned with the warm seasons, and (2) a more evenly distributed abundance of animals during breeding seasons, aligned with the cold seasons. The breeding period of this species is very extended (Villegas-Amtmann et al. 2009), and the correlation between seasonal abundance changes and the onset of the breeding season suggest that special habitat requirements during this energetically costly period may be a potential driver of the observed movements. Further, in the present study, the small beach of PO, which primarily holds adult males not taking part in the breeding groups of WB (Fig. A1 in the Appendix), did not demonstrate seasonal changes in its number of animals, also supporting the hypothesis of breeding activity as a driver of seasonal movements. Although the present study itself does not allow us to determine the potential advantages that movements would represent for this species, it is likely that females are displaying small-scale distribution changes to reduce the high density of animals during the breeding period, thereby increasing the availability of shoreline habitat that provides rapid access to the sea and favors the mother-pup meeting after each feeding sojourn (Trillmich 1986). Further, the greater availability of rocky areas provided by these new places might be an important feature for females when choosing the most suitable habitat for pupping and raising their young. Rocky areas are essential for sea lion pups in providing shaded areas and small swimming pools that are suitable for acquiring swimming skills (Limberger et al. 1986, González-Suárez \& Gerber 2008). Pinnipeds inhabiting lower latitudes often demonstrate special habitat requirements to avoid thermal stress, and this may lead to changes in habitat use preferences and mating systems, in which males often patrol resting sites that have direct access to the water, which are valued by females (Campagna \& Le Boeuf 1988). In other pinniped species, males defending territories with direct access to water often hold greater numbers of females and have increased copulatory success compared to males patrolling waterless areas (Campagna \& Le Boeuf 1988, Francis \& Boness 1991).

The present results suggest that during the energetically demanding breeding seasons, GSL show special habitat requirements that may drive seasonal movements to rookeries with direct access to water and greater rocky area availability to facilitate their behavioral thermoregulatory mechanisms and improve breeding success. 


\section{CONCLUSIONS}

This study has demonstrated that terrestrial habitat use patterns in a tropical pinniped, the GSL, show temporal variations that are strongly influenced by environmental variability on a diurnal and seasonal scale. The correlation between the observed changes in microhabitat use and the environmental variables of air temperature and weather conditions suggest that the GSL shows different preferences as a behavioral adaptation to enhance the effectiveness of its thermoregulatory mechanisms. A novel seasonal pattern of distribution change for tropical pinnipeds is also described and may be associated with specific habitat requirements during the breeding season and linked to thermoregulatory mechanisms. Further, we described and analyzed for the first time the use of artificial floating substrates by GSL as an extension of their own terrestrial habitat, and linked this haul-out behavior to environmental parameters. This is an example of a successful management tool that can provide suitable habitat and enhance the effectiveness of thermoregulatory processes that may have potential applications for other pinnipeds.

Finally, this study highlights the importance of including temporal dynamics in the conservation planning for this tropical pinniped. Because having a suitable haul-out site can be paramount for GSL's physiological requirements and breeding success, enforcing management actions towards habitat preservation that take into account thermoregulatory requirements and breeding activities will help to ensure the long-term survival of this Endangered species.

Acknowledgements. We thank W. Tapia, M. Yépez, J. Torres, and the staff of the Marine Resources Department of the Galapagos National Park Service for providing logistics and permits for this study. We also thank M. Hirschfeld, N. Guevara, F. Rubianes, and all volunteers that helped during the fieldwork. This study was funded by the Galapagos Institute for the Arts and Sciences (GAIAS). I.M.S. was supported by an Erasmus Mundus External Cooperation Window Scholarship provided by the European Commission. K. Kaplan, B. Hopping, and 3 anonymous reviewers helped to improve this manuscript.

\section{LITERATURE CITED}

Alava JJ, Salazar S (2006) Status and conservation of otariids in Ecuador and the Galapagos Islands. In: Sea lions of the world. Alaska Sea Grant College Program, Fairbanks, AK, p 495-519

Alava JJ, Ross PS, Ikonomou MG, Cruz M and others (2011) DDT in endangered Galapagos sea lions (Zalophus wollebaeki). Mar Pollut Bull 62:660-671

Aurioles D, Trillmich F (2008) Zalophus wollebaeki. In: IUCN Red List of Threatened Species, Version 2013.1. IUCN SSC Pinniped Specialist Group. IUCN, Cambridge. www.iucnredlist.org

Bartholomew GA (1970) A model for the evolution of pinniped polygyny. Evolution 24:546-559

Baum JK, Worm B (2009) Cascading top-down effects of changing oceanic predator abundances. J Anim Ecol 78: 699-714

Beentjes MP (2006) Behavioral thermoregulation of the New Zealand sea lion (Phocarctos hookeri). Mar Mamm Sci 22:311-325

Brock PM, Hall AJ, Goodman SJ, Cruz M, Acevedo-Whitehouse K (2013) Immune activity, body condition and human-associated environmental impacts in a wild marine mammal. PLoS ONE 8:e67132

Burnham KP, Anderson DR (2002) Model selection and multimodel inference: a practical information-theoretic approach, 2nd edn. Springer-Verlag, New York, NY

> Campagna C, Le Boeuf B (1988) Thermoregulatory behaviour in the sea lion and its effect on the mating system. Behaviour 107:72-90

Carlens H, Lydersen C, Kraft B, Kovaks K (2006) Spring haul-out behavior of ringed seals (Pusa hispida) in Kongsfjorden, Svalbard. Mar Mamm Sci 22:379-393

Costa DP, Weise MJ, Arnould JPY (2006) Potential influences of whaling on the status and trends of pinniped populations. In: Estes JA, Demaster DP, Doak DF, Williams TM, Brownell RL (eds) Whales, whaling and ocean ecosystems. University of California Press, Berkeley, CA, p 344-359

Elorriaga-Verplancken F (2009) Variación isotópica de $\delta$ $15 \mathrm{~N}$ y $\delta 13 \mathrm{C}$ en colágeno dental lobo marino de California Zalophus californianus: patrones históricos y ontogénicos. PhD dissertation, CICIMAR-IPN, La Paz

Francis JM, Boness DJ (1991) The effect of thermoregulatory behavior in the mating system of the Juan Fernandez fur seal, Arctocephalus philippii. Behaviour 119:104-126

- González-Suárez M, Gerber LR (2008) Habitat preferences of California sea lions: implications for conservation. J Mammal 89:1521-1528

Hanna E, Cardillo M (2013) Island mammal extinctions are determined by interactive effects of life history, island biogeography and mesopredator suppression. Glob Ecol Biogeogr 23:395-404

Hindell MA, Bradshaw CJA, Harcourt RG, Guinet C (2003) Ecosystem monitoring: Are seals a potential tool for monitoring change in marine systems? In: Gales N, Hindell MA, Kirkwood R (eds) Marine mammals: fisheries, tourism, and management issues. CSIRO, Collingwood, p 330-343

Hutto RL (1985) Habitat selection by nonbreeding migratory land birds. In: Cody ML (ed) Habitat selection in birds. Academic Press, Orlando, FL, p 455-476

IPCC (2007) Climate change 2007: the physical science basis. Contribution of Working Group I to the Fourth Assessment Report of the Intergovernmental Panel on Climate Change. Solomon S, Qin D, Manning M, Chen Z and others (eds) Cambridge University Press, Cambridge

Jeglinski JWE, Werner C, Robinson PW, Costa DP, Trillmich F (2012) Age, body mass and environmental variation shape the foraging ontogeny of Galapagos sea lions. Mar Ecol Prog Ser 453:279-296 
Jemison LA, Pendleton GW, Wilson CA (2001) Harbour seal population trends and factors influencing counts at Nanvak Bay, northern Bristol Bay Alaska. In: Harbour seal investigations in Alaska. Annual report for NOAA award NA87FXO300. Alaska Department of Fish and Game, Division of Wildlife Conservation, Anchorage, AK p 53-70

Jonker FC, Bester MN (1998) Seasonal movements and foraging areas of adult southern female elephant seals, Mirounga leonina, from Marion Island. Antarct Sci 10: 21-30

> Kappel CV (2005) Losing pieces of the puzzle: threats to marine, estuarine, and diadromous species. Front Ecol Environ 3:275-282

Krieber M, Barrette C (1984) Aggregation behaviour of harbour seals at Forillon National Park, Canada. J Anim Ecol 53:913-928

> Leeney RH, Broderick AC, Mills C, Sayer S, Witt MJ, Godley BJ (2010) Abundance, distribution and haul-out behaviour of grey seals (Halichoerus grypus) in Cornwall and the Isles of Scilly, UK. J Mar Biol Assoc UK 90:1033-1040

Limberger D, Trillmich F, Biebach H, Stevenson R (1986) Temperature regulation and microhabitat choice by freeranging Galapagos fur seal pups (Arctocephalus galapagoensis). Oecologia 69:53-59

McCullagh P, Nelder JA (1989) Generalized linear models Chapman \& Hall, London

$>$ Meise K, Krüger OB, Piedrahita P, Trillmich F (2013) Site fidelity of male Galápagos sea lions: a lifetime perspective. Behav Ecol Sociobiol 67:1001-1011

- Montgomery RA, Ver Hoef JM, Boveng PL (2007) Spatial modeling of haul-out site use by harbor seals in Cook Inlet, Alaska. Mar Ecol Prog Ser 341:257-264

Myers RA, Baum JK, Sheperd TD, Powers SP, Peterson CH (2007) Cascading effects of the loss of apex predatory sharks from a coastal ocean. Science 315:1846-1850

Norris AL, Houser DS, Crocker DE (2010) Environment and activity affect skin temperature in breeding adult male elephant seals (Mirounga angustiostris). J Exp Biol 213: 4205-4212

Odell DK (1974) Behavioural thermoregulation in the California sea lion. Behav Biol 10:231-237

Páez-Rosas D, Aurioles-Gamboa D, Alava JJ, Palacios DM (2012) Stable isotopes indicate differing foraging strategies in two sympatric otariids of the Galapagos Islands. J Exp Mar Biol Ecol 424-425:44-52

Palacios DM (2004) Seasonal patterns of sea-surface temperature and ocean color around the Galapagos: regional and local influences. Deep-Sea Res II 51:43-57

Pauli BD, Terhume JM (1987) Tidal and temporal interaction on harbor seals haul-out patterns. Aquat Mamm 13: 93-95

R Development Core Team (2008) R: a language and environment for statistical computing. R Foundation for Statistical Computing, Vienna. Available at: www.r-project.org
Riedman M (1989) The pinnipeds: seals, sea lions, and walruses. University of California Press, Berkeley

Rosa R, Seibel BA (2008) Synergistic effects of climate related variables suggest future physiological impairment in a top oceanic predator. Proc Natl Acad Sci USA 105:20776-20780

Rosas FCW, Pinedo MC, Marmontel M, Haimovici M (1994) Seasonal movements of the South American sea lion (Otaria flavescens) off the Rio Grande do Sul coast, Brazil. Mammalia 58:51-59

Salazar S (2003) Impacts of the Jessica oil spill on sea lion (Zalophus wollebaeki) populations. Mar Pollut Bull 47: 313-318

Sigler MF, Womble JN, Vollenweider JJ (2004) Availability to Steller sea lions (Eumetopias jubatus) of a seasonal prey resource: a prespawning aggregation of eulachon (Thaleichthys pacificus). Can J Fish Aquat Sci 61: 1475-1484

Thompson SD, Ono KA, Oftedal OT, Boness DJ (1987) Thermoregulation and resting metabolic rate of California sea lion pups. Physiol Zool 60:730-736

Trillmich F (1986) Attendance behaviour of Galapagos sea lions. In: Gentry RL, Kooyman GL (eds) Fur seals: maternal strategies on land and at sea. Princeton University Press, Princeton, NJ, p 196-208

Trillmich F, Limberger D (1985) Drastic effects of El Niño on Galapagos pinnipeds. Oecologia 67:19-22

Twiss SD, Wright NC, Dunstone N, Redman P, Moss S, Pomeroy P (2002) Behavioral evidence of thermal stress from overheating in UK breeding grey seals. Mar Mamm Sci 18:455-468

Villegas-Amtmann S, Atkinson S, Costa DP (2009) Low synchrony in the breeding cycle of Galapagos sea lions revealed by seasonal progesterone concentrations. J Mammal 90:1232-1237

White FN, Odell DK (1971) Thermoregulatory behaviour of the northern elephant seal, Mirounga angustirostris. J Mammal 52:758-774

Whittow GC, Ohata CA, Matsuura DT (1971) Behavioural control of body temperature in the unrestrained California sea lion. Commun Behav Biol 6:87-91

- Wolf JBW, Trillmich F (2007) Beyond habitat requirements individual fine-scale site fidelity in a colony of the Galapagos sea lion (Zalophus wollebaeki) creates conditions for social structuring. Oecologia 152:553-567

> Wolf JBW, Kauermann G, Trillmich F (2005) Males in the shade: habitat use and sexual segregation in the Galapagos sea lion (Zalophus californianus wollebaeki). Behav Ecol Sociobiol 59:293-302

Womble JN, Sigler MF, Willson MF (2009) Linking seasonal distribution patterns with prey availability in a centralplace forager, the Steller sea lion. J Biogeogr 36:439-451

Yodzis P (2001) Culling predators to protect fisheries: a case of accumulating uncertainties. Trends Ecol Evol 16: 282-283 
Appendix. Sex ratio of Galapagos sea lions found at the study sites in Wreck Bay, Galapagos

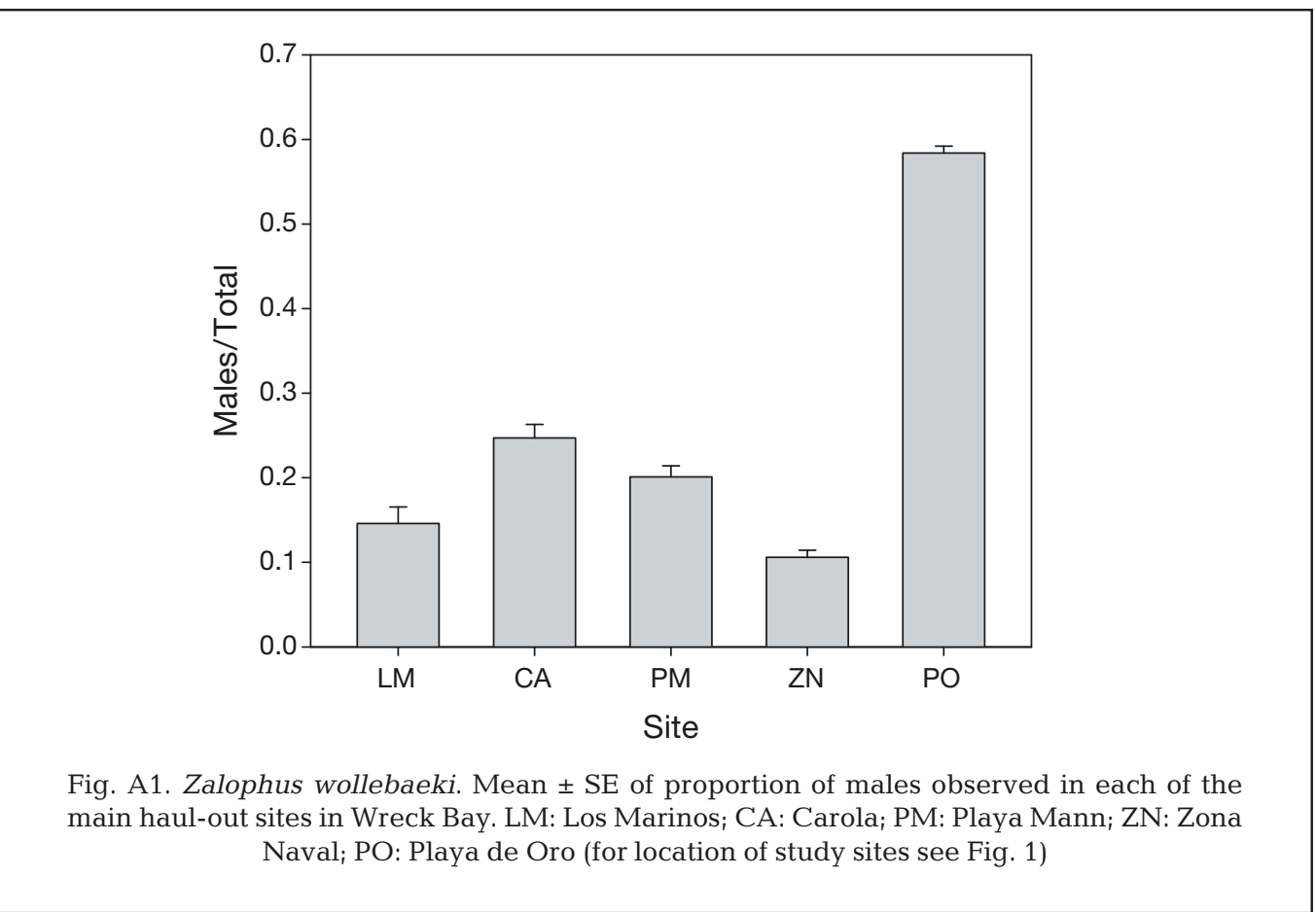

Editorial responsibility: Clive McMahon, Darwin, Australia
Submitted: May 16, 2013; Accepted: November 22, 2013

Proofs received from author(s): March 5, 2014 